\title{
Short communication: Isolation of a whey fraction rich in $\alpha$-lactalbumin from skim milk using tangential flow ultrafiltration
}

\author{
B. Holland, ${ }^{\star}$ J. Kackmar, $†$ and M. Corredig ${ }^{\star 1}$ \\ *Department of Food Science, University of Guelph, Guelph, Ontario, Canada, N1G2W1 \\ †SmartFlow Technologies, 1000 Goodworth Dr., Apex, NC 27539-3869
}

\begin{abstract}
The objective of this research was to evaluate the potential for separating $\alpha$-lactalbumin from pasteurized milk by using tangential flow membrane filtration. Filtration was carried out with a Purosep 7000 series membrane filtration unit (SmartFlow Technologies) with a regenerated cellulose membrane at $26^{\circ} \mathrm{C}$ and a transmembrane pressure of $186 \mathrm{kPa}$. The protein in the permeate was $>80 \% \alpha$-lactalbumin, and this product could be used as a value-added ingredient in nutritional products.
\end{abstract}

Key words: $\alpha$-lactalbumin, ultrafiltration, skim milk, whey protein isolate

\section{Short Communication}

Ultrafiltration is a membrane filtration technology widespread in the dairy industry. The filtration units commonly used in milk processing use either ceramic or polymeric spiral-wound filters. Ceramic filters are heat tolerant, allow operation at high pressures, and are resistant to caustic cleaning solutions (Elwell and Barbano, 2006). Spiral-wound modules, because of their construction geometry, have a larger surface area and are less expensive than ceramic modules, and they are often used for the separation of milk products (Baruah et al., 2006; Elwell and Barbano, 2006). All membrane systems are very prone to fouling, and this causes flux reductions and a decrease in the nominal pore size of the membrane, limiting membrane selectivity (Marshall et al., 1993; Kim and Zydney, 2006; Cowan and Ritchie, 2007).

Increasing attention has been focused on filtration techniques that modify the protein composition of milk or modify the ratio of the different components, to produce high-value functional ingredients in either the retentate fraction or the permeate fraction. For exam-

Received January 31, 2012.

Accepted May 20, 2012.

${ }^{1}$ Corresponding author: milena.corredig@uoguelph.ca ple, it is possible, using membrane filtration, to obtain fractions rich in milk fat globule membrane material (Corredig et al., 2003) or permeate fractions containing whey proteins with or without $\beta$-CN (van Hekken and Holsinger, 2000; Holland et al., 2011).

The present research hypothesized that the use of a low-fouling membrane system would allow for the selective separation of $\alpha$-LA from skim milk. The 2 major whey proteins in milk are $\beta$-LG and $\alpha$-LA, with a molecular weight of 18 and $14.2 \mathrm{kDa}$, respectively (Swaisgood, 1995). $\beta$-Lactoglobulin is the most abundant protein in whey, and in its native form in milk (at $\mathrm{pH}>5.5$ ), it exists as a dimer (Swaisgood, 1995). The other major whey protein, $\alpha$-LA, is rich in the AA tryptophan and cysteine, and its enrichment in a whey protein fraction would be highly desirable for nutritional value-added ingredients (Rudloff and Kunz, 1997).

It has previously been reported that after reconstituting a whey protein isolate in appropriate buffers to maximize the charge and size differences between $\alpha$-LA and $\beta$-LG, it is possible to separate the 2 proteins by using tangential flow filtration (Cheang and Zydney 2004; Almecjia et al., 2007). However, this approach has been reported only on a laboratory scale.

The current research used an upscalable plate and frame filtration module (using a Purosep system with Optisep filter modules, both from SmartFlow Technologies, Apex, NC). The UF modules contained polymeric filtration membranes of various materials, supported by a rigid epoxy casing. The special fluid dynamics within the cartridge provide even flow across the membrane, thereby reducing fouling. The objective of this study was to determine the potential for isolating a fraction rich in $\alpha$-LA by UF of pasteurized skim milk.

All experiments were carried out using pasteurized skim milk (Crown Dairy Ltd., Agropur, Guelph, ON, Canada). The filtration system a customized Purosep PT system (SmartFlow Technologies). The system was assembled with 7000 series membranes (0.46 to 1.86 $\mathrm{m}^{2}$ ) with flow rates up to $340 \mathrm{~L} / \mathrm{min}$ and pressures of $21 \mathrm{kPa}$. The pressure on the inlet and outlet sides of the filter cartridge, temperature of recirculation, and 
flow of both the retentate and permeate streams were recorded.

Three different UF membranes with a molecular weight cutoff of approximately $100 \mathrm{kDa}$ were tested in this study: (1) a regenerated cellulose membrane (RC100, SmartFlow Technologies), (2) a polysulfone membrane (BTS 80, Pall Corporation, East Hills, NY), and (3) a polyether sulfone membrane (Biomax 100, Millipore, Billerica, MA). Although all membranes showed good transmission of $\alpha-\mathrm{LA}$, during preliminary testing, the $\mathrm{RC} 100$ membrane seemed to show the highest rates of transmission; therefore, optimization was carried out with this membrane, and the data reported in this communication are derived from the experiments using regenerated cellulose (RC-100 with a nominal cutoff of $100 \mathrm{kDa})$.

A range of temperatures $\left(15\right.$ to $\left.45^{\circ} \mathrm{C}\right)$ and transmembrane pressures (130 to $270 \mathrm{kPa}$ ) were tested. The pressure was calculated based on pressure at the inlet and outlet sides of cartridge. The present article reports the results derived from filtration of skim milk at $25^{\circ} \mathrm{C}$ using RC-100 membranes, an inlet pressure of $228 \mathrm{kPa}$, and an outlet pressure of approximately $89 \mathrm{kPa}$, yielding a transmembrane pressure of $165 \mathrm{kPa}$. Skim milk (80-kg batches) was processed, concentrating to either $6 \times$ or $2 \times$ and recycling the permeate at this concentration. Samples of retentate and permeate were taken at various concentration points (i.e., $2 \times$ and $3 \times$, based on the volume of permeate reduction).

The amounts of $\alpha-\mathrm{LA}$ and $\beta-\mathrm{LG}$ present in the permeate were determined using size-exclusion HPLC. After filtration through a $0.2-\mu \mathrm{m}$ filter (Millipore), permeate samples $(50 \mu \mathrm{L})$ were injected on a sizeexclusion column with a guard column (Biosep 2000, Phenomenex Ltd., Torrance, CA). Samples were eluted isocratically using $50 \mathrm{~m} M \mathrm{PBS}, \mathrm{pH} 7.4$, and a Thermal Separation HPLC instrument (Thermo Fisher Scientific, Mississauga, ON, Canada). Data analysis was carried out using the manufacturer's software (Chromquest version 4.1, Thermo Fisher Scientific). Quantification was carried out after calibration with standard curves constructed by using pure $\alpha$-LA and $\beta-L G$ previously fractionated from whey, according to established methods (Andrews et al., 1985). The relative abundance of $\alpha$-LA was quantified $[\alpha-\mathrm{LA} /(\alpha-\mathrm{LA}$ $+\beta-\mathrm{LG})]$. To evaluate the extent of denaturation of the protein during filtration, thermal transitions of the protein isolates were measured by microcalorimetry (VP-DSC, Microcal Inc., North Hampton, MA). Permeate samples (20-kg batches) were dialyzed against deionized water for $48 \mathrm{~h}$ to reduce the lactose and ionic content. The reference cell was loaded with a sample of whey protein-free permeate, also prepared by UF
(Holland et al., 2011). This permeate was also dialyzed against water. Solutions were held at $30^{\circ} \mathrm{C}$ for $15 \mathrm{~min}$, run at a $1^{\circ} \mathrm{C} / \mathrm{min}$ scan rate to $100^{\circ} \mathrm{C}$, and then cooled to $20^{\circ} \mathrm{C}$, as reported previously (Corredig and Dalgleish 1994). Enthalpy $(\Delta \mathrm{H})$ and the denaturation temperature midpoint $(\mathrm{Td})$ were analyzed by Origin software version 7.0 (Microcal Inc.).

When filtration was conducted on pasteurized skim milk with the milk reaching a $2 \times$ concentration (based on volume reduction), the system maintained in a steady state, and the permeate recycled, the permeate and retentate flow rates were constant over $4 \mathrm{~h}$ of processing at a transmembrane pressure of $165 \mathrm{kPa}$. As expected, during concentration of the retentates, the flux of permeate decreased during concentration. Figure 1 depicts the permeate flux through the membrane during filtration of skim milk up to a $6 \times$ concentration. The flux remained relatively constant between $2 \times$ and $4 \times$ concentrations to approximately $20 \mathrm{~L} / \mathrm{m}^{2} \cdot \mathrm{h}$. It is important to note that because the focus of this work was to determine the potential for separation of a high$\alpha$-LA fraction, the filtration process may still need to be optimized to obtain better flow rates and permeate fluxes.

To determine the amount of protein present in the retentate fraction or permeate fraction, the 2 main proteins present, $\alpha-\mathrm{LA}$ and $\beta-\mathrm{LG}$, were quantified in the permeate samples obtained during filtration. Chromatography showed only 2 peaks, corresponding to

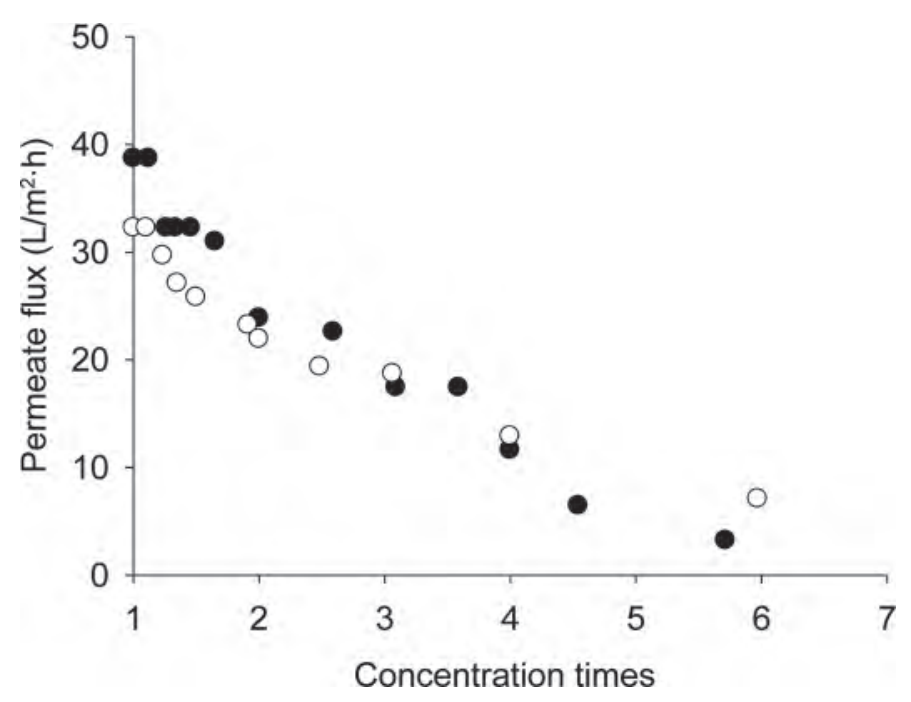

Figure 1. Permeate flux measured during filtration with the RC100 UF membrane (SmartFlow Technologies, Apex, NC). The flux is plotted as a function of concentration $(2 \times, 3 \times, 6 \times)$ of the milk, based on volume reduction. Experiments began with $80 \mathrm{~kg}$ of pasteurized skim milk. Different symbols represent 2 separate replicate experiments. 
Table 1. Relative abundance of $\alpha-\mathrm{LA}$, calculated as $[\alpha-\mathrm{LA} /(\alpha-\mathrm{LA}+$ $\beta-\mathrm{LG})]$, in the permeate at various stages of $\mathrm{UF}^{1}$

\begin{tabular}{lc}
\hline Sample & $\begin{array}{c}\alpha-\mathrm{LA} \\
\text { (\% of total protein) }\end{array}$ \\
\hline Initial permeate & $79 \pm 7$ \\
Permeate & $88 \pm 9$ \\
$2 \times$ & $86 \pm 7$ \\
$3 \times$ & $85 \pm 9$ \\
$4 \times$ & $68 \pm 2$ \\
$6 \times$ & $98 \pm 1$ \\
Pooled permeate & $86 \pm 8$ \\
$20 \mathrm{~kg}$ & $93 \pm 8$ \\
$40 \mathrm{~kg}$ & $83 \pm 3$ \\
$54 \mathrm{~kg}$ & $93 \pm 3$ \\
$66 \mathrm{~kg}$ & \\
\hline Pooled permeate after a final $6 \times$ concentration & \\
\hline
\end{tabular}

${ }^{1}$ The stages are indicated as levels of volume reduction. Permeates are either $10-\mathrm{mL}$ samples or pooled batches $(20 \mathrm{~kg})$. Filtration was performed using an RC-100 membrane (SmartFlow Technologies, Apex, NC) with $165 \mathrm{kPa}$ of transmembrane pressure. The temperature was maintained at approximately $25^{\circ} \mathrm{C}$ up to a $6 \times$ concentration. Values are means and SD of 2 separate filtration experiments.

the elution of $\alpha$-LA and $\beta$-LG. The amounts of whey proteins present in the permeates were quantified using standards, and the relative abundance (\%) of $\alpha-\mathrm{LA}$ in the permeate at the various stages of concentration is shown in Table 1 . The $\alpha$-LA remained above approximately $80 \%$ throughout the process. The isolation seemed to be the most effective at the early stages of filtration up to a $4 \times$ concentration, when the system operated at optimal flux. At the higher rates of volume reduction, the operating conditions may have not been optimal for transmission of the protein. Filtration was also carried out at a steady state for a $2 \times$ concentration and recycling of the permeate. The relative abundance of $\alpha$-LA in the permeate is summarized in Table 2 . The permeation of $\alpha$-LA continued over time, with very little change in the relative abundance of the protein, in agreement with the fact that the processing parameters also remained constant over the $4 \mathrm{~h}$ of the pilot plant runs.

Table 2. Relative abundance of $\alpha-\mathrm{LA}$, calculated as $[\alpha-\mathrm{LA} /(\alpha-\mathrm{LA}+$ $\beta-L G)]$, in the permeate at various stages of $U^{1}$

\begin{tabular}{lc}
\hline Sample & $\alpha-\mathrm{LA}(\%)$ \\
\hline Initial permeate & 80 \\
Permeate & 87 \\
$2 \times$ & 99 \\
$2 \times, 60 \mathrm{~min}$ & 97 \\
$2 \times, 120 \mathrm{~min}$ & 94 \\
$2 \times, 240 \mathrm{~min}$ &
\end{tabular}

\footnotetext{
${ }^{1}$ Samples of permeate $(10 \mathrm{~mL})$ were taken at various time points while running the system at a steady state at a $2 \times$ concentration. Results are means of 2 replicate experiments. The $\mathrm{CV}$ was $<10 \%$.
}

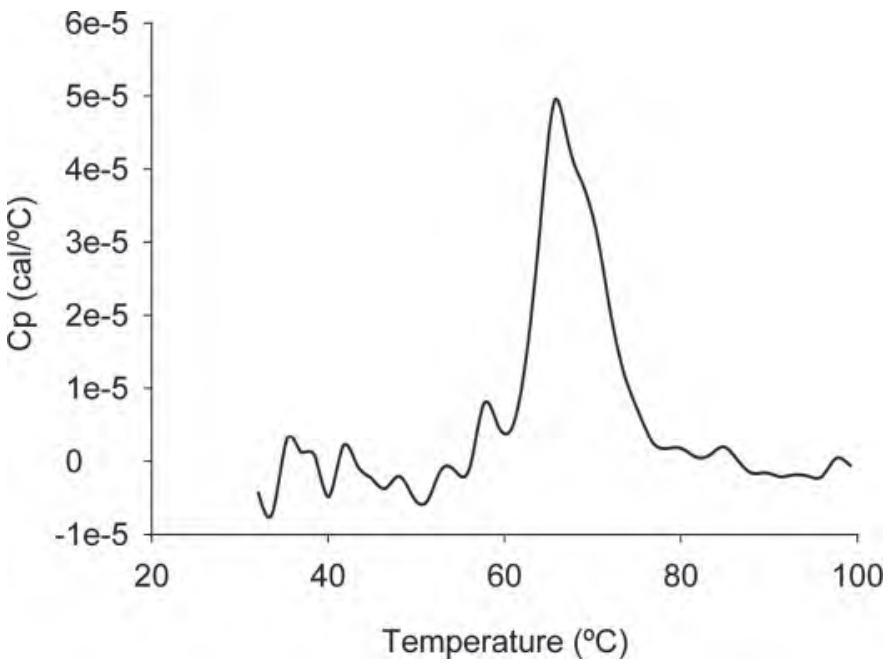

Figure 2. Thermal transition measured by microcalorimetry (VPDSC, Microcal Inc., North Hampton, MA) for the permeate sample after a $4 \times$ concentration of the milk. Samples were dialyzed against deionized water, and the reference was the permeate (whey protein free) dialyzed against water. $\mathrm{Cp}=$ change in heat capacity.

In addition to chromatographic analysis, the permeate was tested by microdifferential scanning calorimetry to determine possible changes in the thermal transition of the protein. This technique has previously been used to observe structural changes in globular proteins (Corredig and Dalgleish, 1994). In agreement with the concentration data, only $1 \alpha$-LA peak was measured, and the thermograms (Figure 2) indicated that the isolation process did not cause structural changes to the protein. The values obtained for a peak maximum at $66.2^{\circ} \mathrm{C}$ and an enthalpy of denaturation of $144.7 \mathrm{~kJ} / \mathrm{mol}$ were in agreement with values reported in the literature of $67.6^{\circ} \mathrm{C}$ and $158 \mathrm{~kJ} / \mathrm{mol}$ (Corredig and Dalgleish, 1994).

Using the Purosep filtration system with regenerated cellulose membranes resulted in the separation of $10 \%$ of the total $\alpha$-LA from pasteurized skim milk. The results confirmed that a lower extent of fouling increased the selectivity of the membrane, achieving a permeate with a minimum $80 \%$ purity of $\alpha$-LA.

\section{REFERENCES}

Almecjia, M., R. Ibanez, A. Guadix, and E. Guadix. 2007. Effect of pH on the fractionation of whey proteins with a ceramic ultrafiltration membrane. J. Membr. Sci. 288:28-35.

Andrews, A. T., M. D. Taylor, and A. J. Owen. 1985. Rapid analysis of bovine milk proteins by fast liquid chromatography. J. Chromatogr. A 348:177-185.

Baruah, G., A. Nayak, and G. Belfort. 2006. Scale-up from laboratory microfiltration to a ceramic pilot plant: Design and performance. J. Membr. Sci. 274:56-63. 
Cheang, B., and A. L. Zydney. 2004. A two-stage ultrafiltration process for fractionation of whey protein isolate. J. Membr. Sci. 231:159-167.

Corredig, M., and D. G. Dalgleish. 1994. A differential microcalorimetric study of whey proteins and their behaviour in oil-in-water emulsions. Coll. Surf. B Biointerfaces 4:411-422.

Corredig, M., R. R. Roesch, and D. G. Dalgleish. 2003. Production of a novel ingredient from buttermilk. J. Dairy Sci. 86:2744-2750.

Cowan, S., and S. Ritchie. 2007. Modified polyethersulfone (PES) ultrafiltration membranes for enhanced filtration of whey proteins. Sep. Sci. Technol. 42:2405-2418.

Elwell, M. W., and D. M. Barbano. 2006. Use of microfiltration to improve fluid milk quality. J. Dairy Sci. 89(E. Suppl.):E20-E30.

Holland, B., M. Corredig, and M. Alexander. 2011. Gelation of casein micelles $\beta$-casein reduced milk prepared using membrane filtration. Food Res. Int. 44:667-671.
Kim, M., and A. Zydney. 2006. Theoretical analysis of particle trajectories and sieving in a two-dimensional cross-flow filtration system. J. Membr. Sci. 281:666-675.

Marshall, A. D., P. A. Munro, and G. Trägardh. 1993. The effect of protein fouling in microfiltration and ultrafiltration on permeate flux, protein retention and selectivity: A literature review. Desalination 91:65-108.

Rudloff, S., and C. Kunz. 1997. Protein and nonprotein nitrogen components in human milk, bovine milk, and infant formula: Quantitative and qualitative aspects in infant nutrition. J. Pediatr. Gastroenterol. Nutr. 24:328-344.

Swaisgood, H. E. 1995. Characteristics of milk. Pages 842-876 in Food Chemistry. 3rd ed. O. R. Fennema, ed. Marcel Dekker, New York, NY

van Hekken, D. L., and V. H. Holsinger. 2000. Use of cold microfiltration to produce unique $\beta$-casein enriched milk gels. Lait 80:69-76. 